\section{REVISTA}

Actualidades Investigativas en Educación http://revista.inie.ucr.ac.cr/

ISSN 1409-4703

\title{
LA EDUCACIÓN INCLUSIVA Y LINEAMIENTOS PROSPECTIVOS DE LA FORMACIÓN DOCENTE: UNA VISIÓN DE FUTURO
}

INCLUSIVE EDUCATION AND PROSPECTIVE GUIDELINES FOR TEACHER TRAINING: A FUTURISTIC VISION

\author{
Volumen 15, Número 2 \\ Mayo - Agosto \\ pp. 1-33
}

Este número se publicó el $1^{\circ}$ de mayo de 2015

DOI: http://dx.doi.org/10.15517/aie.v15i2.18534

Cristina Castillo Briceño

Revista indizada en REDALYC, SCIELO

Revista distribuida en las bases de datos:

CATÁLOGO DE LATINDEX, IRESIE, CLASE, DIALNET, DOAJ, E-REVIST@S, SHERPA/ROMEO, QUALIS, MIAR

Revista registrada en los directorios:

ULRICH'S, REDIE, RINACE, OEI, MAESTROTECA, PREAL, CLACSO 


\title{
LA EDUCACIÓN INCLUSIVA Y LINEAMIENTOS PROSPECTIVOS DE LA FORMACIÓN DOCENTE: UNA VISIÓN DE FUTURO INCLUSIVE EDUCATION AND PROSPECTIVE GUIDELINES FOR TEACHER TRAINING: A FUTURISTIC VISION
}

\author{
Cristina Castillo Briceño ${ }^{1}$
}

\begin{abstract}
Resumen: El artículo se propone valorar una visión de futuro de la educación inclusiva con el fin de brindar lineamientos prospectivos en torno a la formación docente. Para lo anterior, se realizó una investigación documental por medio de la detección, acceso, selección, revisión y análisis del material pertinente de diversos escenarios y autores que han trabajado aspectos vinculados a la temática del objetivo propuesto. Los resultados muestran que los requerimientos de la sociedad actual demandan una preparación académica más integral y humana para afrontar una realidad cada vez más compleja y dar respuestas de calidad en la formación de un docente reflexivo y respetuoso de la diversidad, capaz de construir escenarios de aprendizaje y garantizar una educación inclusiva. Para las unidades de desarrollo docente la educación inclusiva constituye una oportunidad para hacer la tarea educativa de maneras diferentes. Para ello, es necesario articular teoría y práctica, tener conciencia de las teorías que se aplican, propiciar espacios reflexivos para ampliar la percepción de lo que significa educar, en y para la diversidad. Por lo tanto, avanzar hacia una educación inclusiva requiere partir de la realidad del entorno, tener claro hacia dónde se orienta la educación e implementar ambientes adecuados. Las conclusiones señalan que la educación inclusiva en la formación docente se constituye en una herramienta para atender la diversidad: oportunidad e igualdad para todos.
\end{abstract}

Palabras clave: EDUCACIÓN INCLUSIVA, FORMACIÓN DOCENTE, LINEAMIENTOS PROSPECTIVOS, VISIÓN DE FUTURO, DIVERSIDAD

\begin{abstract}
The paper aims at assessing a vision of inclusive education in order to provide prospective guidelines regarding teachers' training. For this, a documentary research was conducted by means of detection, access, selection, review and analysis of relevant material from different scenarios and authors who have approached issues related to the subject. The results show that the requirements of today's society demand a more comprehensive and humane academic preparation to face an increasingly complex reality and to provide quality answers in the training of a respectful and thoughtful educator of diversity, able to construct learning and ensure an inclusive education. For the units concerning the teaching development, inclusive education is an opportunity to perform the educational task in different ways. Consequently, it is necessary to articulate both theory and practice, be aware of the theories being applied, foster reflective spaces to expand the perception of what to educate in and for diversity means. Therefore, progress towards inclusive education requires educators to start from the reality of the environment, to have a clear idea about where education is oriented and to implement suitable environments. The findings indicate that inclusive education in teachers' education becomes a tool to address diversity: opportunity and equality for everybody.
\end{abstract}

Key words: INCLUSIVE EDUCATION, TEACHER EDUCATION, GUIDELINES, PERSPECTIVES, DIVERSITY

\footnotetext{
${ }^{1}$ Profesora Asociada, Docente e investigadora de la

Universidad de Costa Rica.
}

Dirección electrónica: cristina.castillo@ucr.ac.cr

Artículo recibido: 29 de setiembre, 2014

Enviado a corrección: 4 de diciembre, 2014

Aprobado: 23 de febrero, 2015 


\section{Introducción}

Históricamente la educación ha sido un factor esencial y un pilar fundamental en el desarrollo humano, una herramienta poderosa en la construcción de las sociedades y una forma de perpetuarla. Es por eso que en el transcurrir del desarrollo de la humanidad siempre ha existido un interés y atención permanentes hacia ella en los diversos sistemas políticos.

Como consecuencia, en las distintas etapas que enmarcan el desarrollo de las sociedades se han realizado diversos esfuerzos para replantear el quehacer educativo, los cuales conducen al abordaje de una educación equitativa y de calidad, gestándose así, las bases de una emergente educación inclusiva desde una mirada prospectiva hacia lo que implica la formación docente, como artífices y responsables de hacer realidad una educación que se centra en el desarrollo de las potencialidades de cada persona. De modo que referenciar educación inclusiva es hablar de inclusión como un quehacer que se viene gestando, mediante esfuerzos múltiples, en diversos escenarios sociales desde hace varias décadas con el propósito de hacer realidad la inserción activa y participativa de los diferentes sujetos en los procesos de desarrollo.

Dentro de este contexto, el artículo tiene como objetivo valorar una visión de futuro acerca de la educación inclusiva con el fin de brindar lineamientos prospectivos en torno a la formación docente.

En el desarrollo del trabajo se presentan cinco apartados, los cuales abordan los diferentes tópicos que fundamentan la formación docente desde la perspectiva de la educación inclusiva. El primero de ellos da a conocer el procedimiento mediante el cual se recolectó la información. Seguidamente, se plantea una conceptualización acerca de la educación inclusiva. En tercer lugar, se exponen los planteamientos alrededor de la valoración de una visión de futuro sobre la formación en educación inclusiva. Posteriormente, se esbozan algunos lineamientos desde la perspectiva de la educación inclusiva necesarios en la formación docente. Finalmente, se presentan las conclusiones.

\section{Metodología}

Para el logro del objetivo propuesto se realizó una revisión documental en torno a la normativa nacional que respalda tanto la formación docente como el derecho a la educación: Ley Fundamental de Educación (1957), Constitución Política de Costa Rica (1949), Ley 7600 de Igualdad de Oportunidades para las Personas con Discapacidad en Costa Rica (1998), 
Ley 8661 Convención sobre los Derechos de las Personas con Discapacidad y su Protocolo Facultativo (2008) y la Política Nacional en Discapacidad 2011-2021 (PONADIS) (2011).

De igual manera, se revisó lo referente a normativas y conferencias internacionales que dan sustento a una educación para todos, a una educación de calidad, a una educación inclusiva: Organización de Naciones Unidas (ONU) $(2006,1990)$, Organización de Naciones Unidas para la Ciencia y la Cultura (UNESCO) (2008).

Asimismo, fueron revisados los aportes de autores de mayor relevancia en relación con el tema, a saber: Ainscow, Booth y Dyson (2006); Ainscow (2001, citado por González, 2008); Arnaiz (2003, 2005); Barnett (2003); Blanco (2000, 2010); Booth (2006); Echeita (2003, 2004, 2006, 2010); Echeíta y Simón (2007); Echeíta y Verdugo (2004, 2009); Essomba ( 2006); García (2005, 2008); Confederación Española de Organizaciones a favor de las Personas con Discapacidad Intelectual (2009); Marchesi (2010); Marchesi, Durán, Climent y Hernández (2009); Casanova (2011); Doré, Wagner y Brunet (2002) y Agencia Europea para el Desarrollo de la Educación del Alumnado con Necesidades Educativas Especiales (2011). En la figura 1 se presentan los momentos de la investigación documental realizada: 


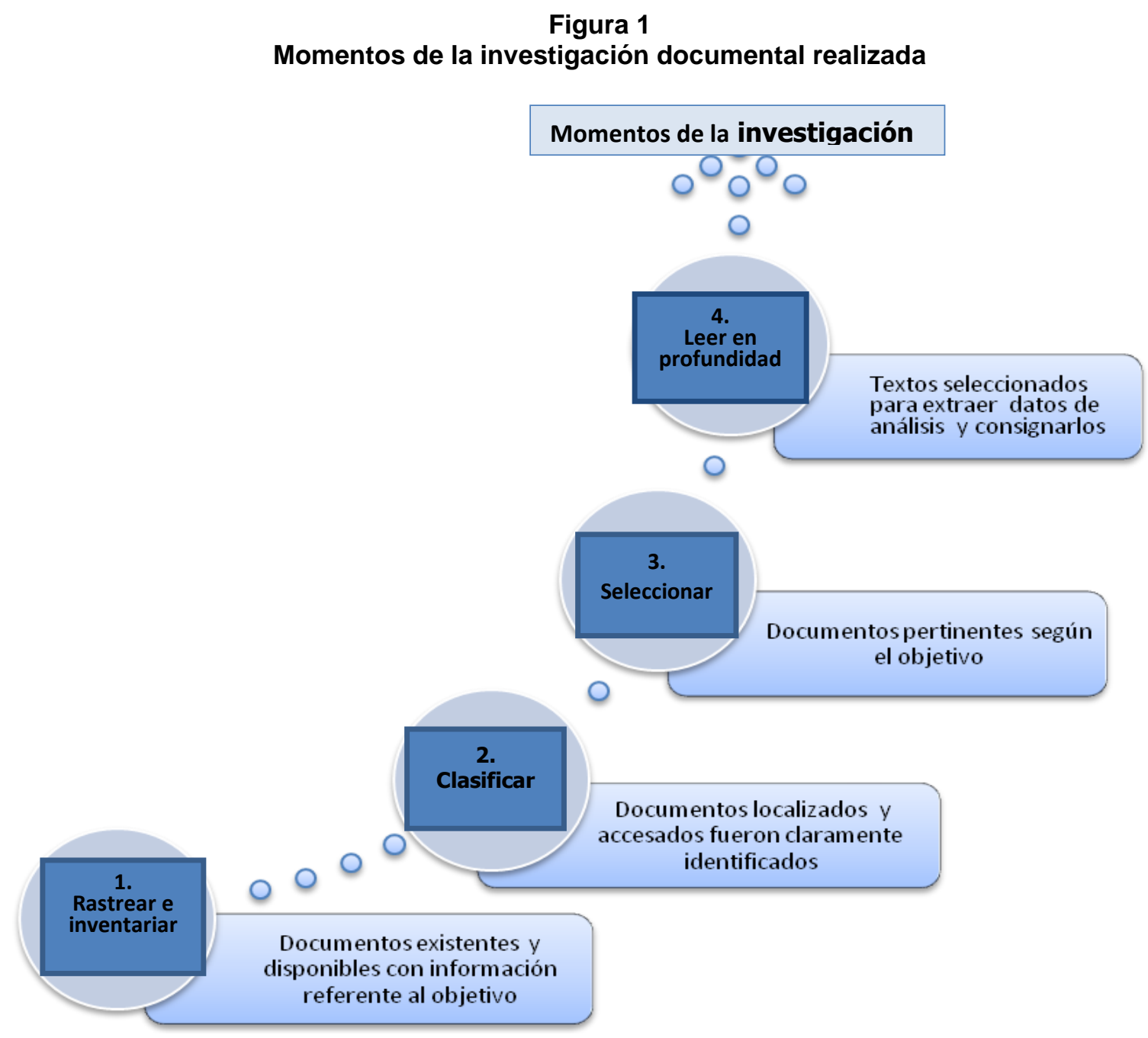

Fuente: Elaboración propia a partir de Universidad Pedagógica Experimental Libertador (2006).

En la investigación documental, el aporte de quien investiga radica en analizar y seleccionar esta información, acoger lo relevante para su investigación de acuerdo con el objetivo planteado para darle un tratamiento posterior, diferente al que tiene la documentación original. Es decir, por medio de la detección, acceso, selección, revisión y análisis del material pertinente de diversos escenarios y autores que han trabajado aspectos vinculados a la temática se extrajo y procesó la información recopilada.

\section{De la educación inclusiva}

Los modelos y sistemas educativos han dependido de las concepciones ideológicas que sustentan el quehacer político de los distintos gobiernos, que se manifiestan en sus constituciones, como una forma de proteger otros derechos, tales como: una educación de 
calidad, de salud, de libertad y como un medio de movilidad social (Venegas, 2006). Por lo tanto, conceptualizar la educación inclusiva desde una sola definición no es posible, pues en la riqueza del vocablo convergen una serie de dimensiones que le imprimen un carácter de complejidad.

No existe un consenso entre los autores más representativos de este movimiento (Ainscow, 2001; Arnaiz, 2003; Dyson, 1999; Stainback y Stainback, 1999) ya que cada uno tiene su propia visión sobre el mismo. Así, por ejemplo, podemos encontrar definiciones tan diferentes y clarificadoras como señala Ainscow (2001, p. 44), "una escuela que no solo acepta la diferencia, sino que aprende de ella", o como definen Stainback y Stainback (1999, pp. 21-35), "es la que educa a todos los estudiantes en la escuela ordinaria”. (Esteve, Ruiz, Tena y Úbeda, 2006, p. 3)

En estas instancias, la educación inclusiva tiene una gran diversidad y amplias aspiraciones y, aunque se reconoce que su abordaje presenta diversos matices en la forma de afrontarla, se le puede concretar como un conjunto de transformaciones educativas que apoyan y dan la bienvenida a la diversidad de toda la población estudiantil, y no sólo a los que presentan necesidades educativas (UNESCO, 2008).

La noción de inclusión no es algo propio del sistema educativo, más bien debería estar en armonía con la noción de una sociedad inclusiva que aprecia ese valor y en la que cada miembro tiene su lugar. Los costes sociales de la exclusión, estigmatización, segregación, alienación, quedan más allá de la responsabilidad del sistema educativo, y hay que buscarlos en la ética de la sociedad en su conjunto. La inclusión está impulsada y dirigida por valores y son nuestros valores y creencias los que modelan la política y la cultura que tenemos y que queremos (UNESCO, 2008 citado por Confederación Española de Organizaciones a favor de las Personas con Discapacidad Intelectual. (2009, p. 34)

Desde esta posición, es claro que un modelo eminentemente técnico de formación docente no preparará a los profesionales en Educación para afrontar los retos de la educación inclusiva, por lo que no se pretende en este apartado dar recetas sobre cómo ha de diseñarse la formación docente, lo que si resulta necesario plantear es lo siguiente: para que el trabajo de los educadores contribuya al logro del ser docente, se requiere desarrollar actitudes, valores, competencias, conocimientos y comprensión adecuados. 
Precisamente por los tiempos de cambio acelerado que se vive en estos momentos, varía día a día la composición de nuestra sociedad (con todas las implicaciones educativas que este hecho implica) y, además, optamos decididamente por un modelo educativo más exigente esperando mejores resultados, tanto escolares como de convivencia social. La consecuencia es un nuevo reto cada día para los profesionales de la educación y, lógicamente, una necesidad de actualización tanto científica como didáctica de modo continuo. (Casanova, 2011, p. 94)

Las necesidades de formación deben atenderse mediante la acción para que no correspondan solamente a preocupaciones o buenas intenciones. Es menester innovar las estrategias formativas, poseer un personal docente y administrativo idóneo y estructuras organizativas congruentes, sin perder el punto medular, el estudiante.

La opción por una educación inclusiva, por una educación de calidad para todos, demanda un profesorado implicado, comprometido, competente, con herramientas que le permitan que todo el alumnado del aula sea capaz de aprender al máximo independientemente de las características que presente; en suma, un profesorado capacitado para gestionar el éxito en las aulas. (Forteza, 2010, p. 8)

La educación inclusiva, como práctica social, comprende un conjunto de valores y principios, estrategias y experiencias destinadas a la democratización de la educación y a una actualización permanente, a través del desarrollo de propuestas pedagógicas que faciliten al estudiantado el derecho de acceso, de participación y de aprendizaje en igualdad de condiciones. Esto es, sin ningún tipo de discriminación que pueda restringir o anular el gozo de este derecho fundamental.

Cuando se piensa en educación se piensa en humanidad, de igual manera, cuando se habla de educación inclusiva se hace referencia a derechos humanos. Los valores son los ejes que orientan la parte formativa en la vida del ser humano y, por lo tanto, conducen también el ámbito educativo y la sociedad en general.

En efecto, el tema de la inclusión no es solamente un asunto educativo o pedagógico, se trata, más bien, de una perspectiva de respeto a los valores comprendidos en los derechos humanos que afectan, particularmente, a los sistemas educativos. Por ello, se encuentran íntimamente vinculadas "la forma de concebir el tipo de sociedad y de bienestar a los que se aspira y la manera en que se concibe el "vivir juntos" (UNESCO, 2008, p 4). 
De este modo, la justicia social, la inclusión social y la educación inclusiva forman una triada indisoluble, en la que subyacen valores tan importantes como el respeto a la diversidad, la equidad, la convivencia de forma solidaria y la tolerancia constructiva. En este sentido, es necesario formar en valores, de manera que cada estudiante sea capaz de ubicarse en una sociedad caracterizada por la multiculturalidad.

La conceptualización de educación inclusiva, mencionada previamente, permite deducir que referirse a dicha temática remite, necesariamente, a valores inherentes al derecho de la educación como un derecho fundamental de toda persona, tal y como se ilustra seguidamente.

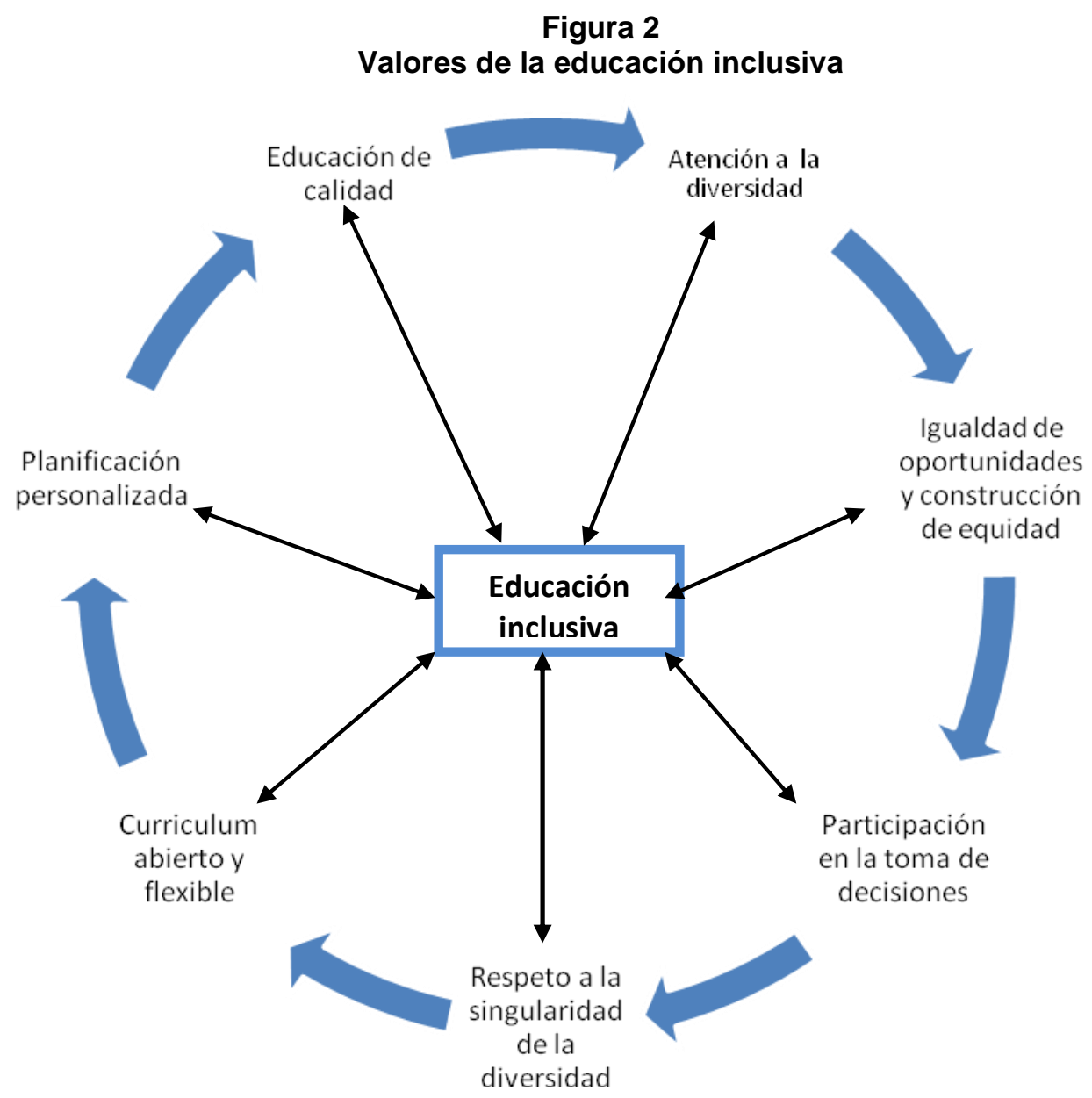

Fuente: Elaboración propia a partir del procesamiento de la información documental

De acuerdo con la figura 2, la educación inclusiva puede ser concebida como un proceso que permite abordar y responder a la diversidad de necesidades educativas de la población estudiantil y enriquecer la calidad de la educación para todos, mediante la 
participación activa en el transcurso de su formación, con un curriculum flexible, respeto a la singularidad y una planificación personalizada. De esta manera, la educación inclusiva brinda respuestas de calidad al amplio espectro de las características particulares de aprendizaje.

La educación inclusiva no corresponde a un nuevo enfoque. Aun así las recientes publicaciones la presentan como una nueva vía del hacer educativo, cuando en realidad su naturaleza diferente consiste en ser una forma de reorientar una dirección ya tomada, cuyo propósito es lograr que la educación, verdaderamente, represente a todo el estudiantado, sin exclusiones. Al respecto, Parrilla (2002, p.2) plantea que "la educación inclusiva tiene que ver con cómo, dónde y por qué, y con qué consecuencias educamos a todos los alumnos" de una comunidad escolar.

\section{Valoración de una visión de futuro}

La valoración de una visión de futuro sobre la educación inclusiva se relaciona con la construcción del futuro, a partir de lo que se hace en el presente en el proceso de formación docente dentro de un contexto dado.

De acuerdo con esta connotación de visión de futuro, una restructuración en el quehacer educativo no es necesariamente el punto de llegada dentro del proceso de formación; más bien, apunta hacia la manera como se va construyendo y de lo que se está realizando en el abordaje de la temática de la educación inclusiva, en la formación del educador. Sin una visión de futuro es como construir un edificio sin planos: sin una idea de cómo se verá terminado y qué se hará para ello. Todas las grandes obras en la humanidad: artísticas, científicas o políticas han sido el resultado de una visión de futuro que fue ejecutada.

Es decir, "todo lo que no se acometa ya, en este momento, supondrá rémoras irrecuperables para nuevas generaciones, una tras otra, que habrán dedicado tiempo y esfuerzo a conseguir una educación absolutamente inadecuada para el presente y el futuro de nuestra sociedad" (Casanova, 2011, p. 22).

En ese sentido, es apropiado plantear que se está frente a realidades educativas desconocidas que reclaman una redefinición del papel del docente y el compromiso de revisar periódicamente los progresos realizados para afianzar como práctica cotidiana el mejoramiento continuo. Dentro de este contexto, se infiere que hay escenarios y oportunidades que vislumbran la oportunidad de sentir el derecho, de emprender la senda de 
la transformación hacia una educación inclusiva conducente a una educación para todos, es decir, hacer realidad la utopía de la educación.

En ella se encuentra el impulso hacia una sociedad más justa y más libre. Entre todos, en este tiempo de esperanzas renovadas, con el esfuerzo colectivo y una pasión sin límites podremos hacer realidad los sueños que hoy aquí y para siempre nos mantendrán unidos. (Marchesi, 2010, p. 15)

En términos más claros, visión de futuro de la educación es construir una imagen de la docencia que se quiere alcanzar, un futuro educativo mejor para todos. Esto significa tomar en cuenta una gran variedad de aspectos, desde metas sencillas como aumentar aulas, matrícula, programas, presupuesto hasta perfilarse hacia una educación de calidad y equitativa. A continuación, en la figura 3 , se presentan algunos componentes de una visión de futuro:

\section{Figura 3}

Componentes de una visión de futuro

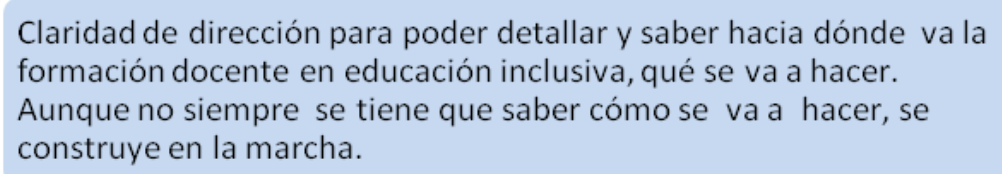

Comunicación para compartir la visión de la formación docente en educación inclusiva que se quiere y así inspirar y motivar a los agentes educativos participantes

Metas claras para trabajar en pro de esa formación docente en educación inclusiva y alcanzar, fortaleciendose el sentido de trabajo en equipo

Evaluar el progreso tanto de logro de metas y aproximación a la visión de futuro de la formación docente en educación inclusiva como de las barreras que se presentan

Fuente: Elaboración propia a partir del procesamiento de la información documental

Es decir, la visión de futuro permite unir grupos, sirve de inspiración para que el colectivo educativo luche por llegar a ese futuro mejor; por otro lado, aporta identidad a los 
centros educativos, al constituirse en una referencia para la toma de decisiones ya que da un sentido de movilización en torno a un ideal compartido.

Esta visión de futuro para la formación docente parte del referente de que la educación inclusiva se constituye en un quehacer educativo, fundamentado en la concepción de derechos humanos. Ella conjuga igualdad y diferencia como valores indisociables y supera el modelo de igualdad formal puesto que pasa a incidir en la realidad social. En ese sentido, busca eliminar las circunstancias históricas de la producción de la exclusión dentro y fuera de los centros educativos, haciendo hincapié en aquellos factores que pueden ser decisivos para construir una educación de calidad para todos.

En el camino hacia una educación Inclusiva, en los procesos de formación docente, surgirán situaciones difíciles de resolver que precisarán de una nueva formación y actualización de los agentes participantes en la tarea educativa, de la reflexión constante, a partir de los entornos educativos y de la realidad. Es una construcción permanente. Probablemente, habrá limitaciones e incertidumbres pero finalmente, se cristalizarán en avances seguros hacia procesos formativos inclusivos que proporcionen los conocimientos, habilidades y las competencias de los futuros docentes, a fin de que estos puedan desempeñarse con seguridad, no sólo en la etapa formativa, sino también en el ejercicio laboral.

Por lo anterior, es trascendental señalar que cuando una unidad formadora de docentes visualiza que asumir la educación inclusiva es un compromiso con la diversidad, posibilita la oportunidad para aprender a hacer la tarea educativa de formas diferentes.

aprender de los demás, compartiendo conocimientos, competencias, reflexiones, creencias... para una educación de calidad, una educación accesible para todos, se sitúa en otro lugar, en aquel en el que es posible avanzar hacia una educación más inclusiva. Y en esta línea, las universidades, responsables de la formación de los futuros educadores, tenemos ahora el desafío de impregnar una orientación inclusiva de la educación en nuestros planes de estudio. (Forteza, 2010, p. 8)

No obstante, hay que comenzar a realizar las acciones necesarias para la mejora de la calidad educativa mediante el abordaje de los derechos humanos y la atención de la diversidad. Lo anterior, es una buena forma de indagar sobre una base de evaluación certera de las diversas situaciones, condiciones, necesidades y recursos de todo tipo, pendientes de alcanzar para seguir avanzando hacia el logro del perfeccionamiento educativo. 
La formación inclusiva sólo puede ser valorada en el contexto en que se sitúa. Es necesario conocer el punto de partida desde el cual se propone avanzar, por lo que es menester valorar algunos de los factores del contexto social y educativo que permiten establecer la situación de partida, tales como: estructura organizativa, clima organizacional, reglamentación y otros.

En el ámbito nacional existen condiciones fértiles que representan un desafío y posibilitan la incorporación de los elementos de educación inclusiva en la formación docente. Para mayor claridad, véase la figura 4.

\section{Figura 4}

\section{Condiciones que facilitan la educación inclusiva en la formación docente}

Desarrollo de una base teórica en educación inclusiva de expertos para ser empleadas como insumos para clarificar y valorar su posición con respecto a ésta, según circunstancias, condiciones culturales y política educativa
La incorporación de declaraciones, convencionese informes internacionales a la política educativa para fomentar el compromiso y desarrollo de programas y actividades en relación con la educación inclusiva

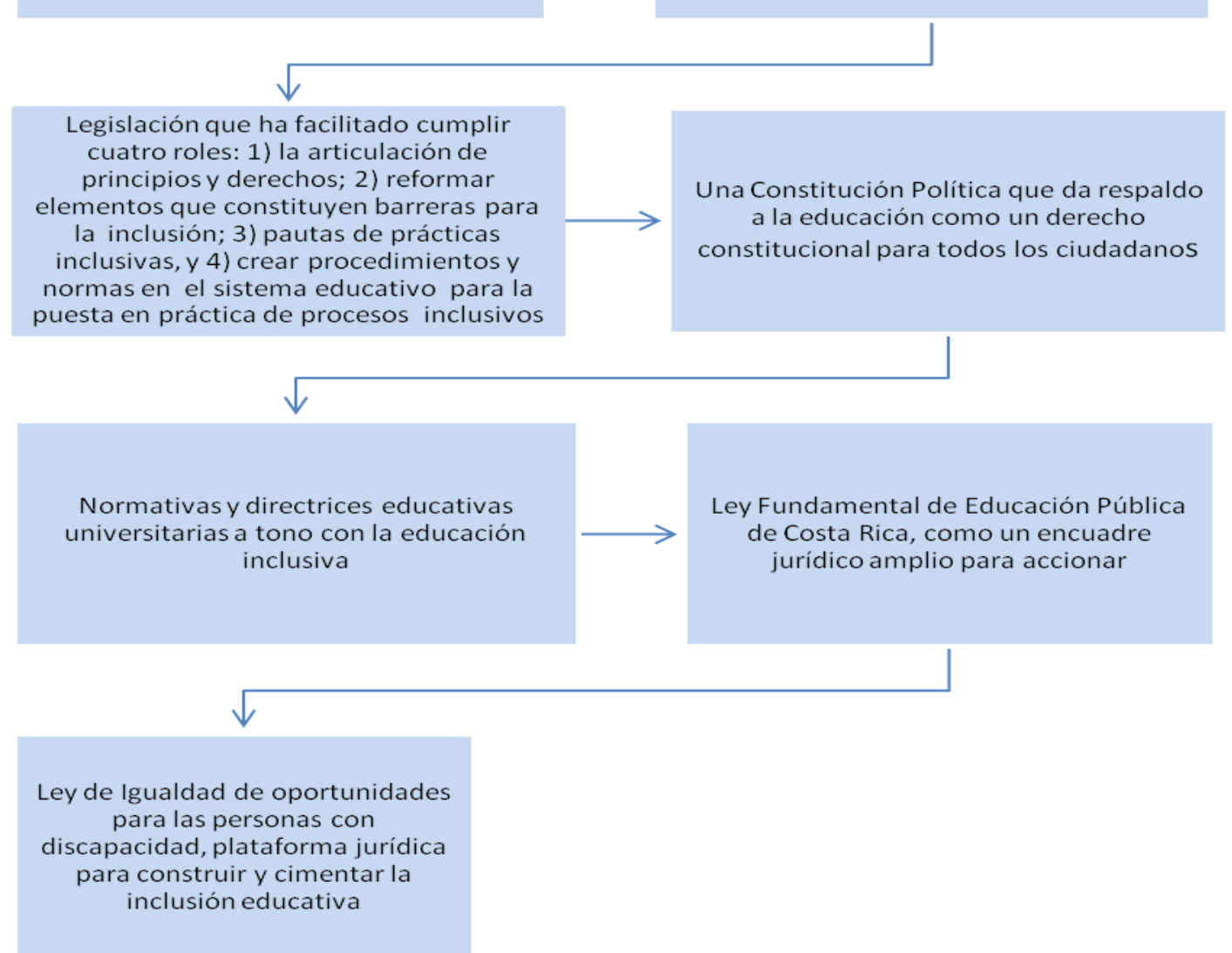

Fuente: Elaboración propia a partir del procesamiento de la información documental 
Consecuente con lo anterior, se infiere que hay un sólido marco legal y voluntad política que posibilita avanzar hacia la educación inclusiva tanto en la clarificación del tema como en la identificación de factores y barreras limitantes, desarrollo de directrices y definición de recomendaciones operativas. Aunado a esto, Costa Rica tiene condiciones que pueden facilitar la movilización que supone apropiarse del cambio en las prácticas educativas, por el papel preponderante que históricamente ha tenido la educación.

Por consiguiente, se aprecia un escenario propicio para la puesta en marcha de programas de formación docente a la luz de la educación inclusiva, de los nuevos modelos de organización educativa, del enfoque de derechos, de adquirir y trasmitir el conocimiento, así como de las nuevas formas contemporáneas de entender la educación, la sociedad y la persona.

\section{Lineamientos prospectivos en torno a la puesta en práctica de la Educación Inclusiva}

Con respecto a este tema, numerosos estudios, algunos ya mencionados anteriormente, coinciden en la necesidad de contar con un personal docente preparado para atender las diversas responsabilidades y tareas que demanda una educación con un enfoque inclusivo. En virtud de esto, surge la necesidad de realizar esfuerzos formativos conducentes a hacer realidad este tipo de educación. Un profesional de la educación llamado docente, "se dedica profesionalmente a educar a otros, quien ayuda a los demás en su promoción humana, quien contribuye a que el alumno despliegue al máximo sus posibilidades, participe activa y responsablemente en la vida social y se integre en el desarrollo de la cultura" (Blat y Marín, 1980, p. 32). De ahí la importancia del papel profesional que desempeñan estos agentes educativos.

Para hacer realidad una visión de futuro en torno a la educación inclusiva en la formación docente, se vislumbran planteamientos prospectivos en torno a principios básicos congruentes con modelos democráticos, preparados para generar redes de colaboración y comunicación, desarrollo de procesos innovadores, gestor de marcos administrativos congruentes con la educación inclusiva, autonomía en la formación, manejo de las tecnologías de la comunicación y la información, incorporación de las dimensiones cognitiva, técnica, socioeconómica y ética, respeto a la diversidad, trabajo en equipo, desarrollo personal y profesional permanente, manejo de metodologías y estrategias de inclusión, los que a continuación se detallan. 


\subsection{Principios básicos}

Son bases que sirven de sustento en la formación docente, desde la perspectiva de la educación inclusiva, se propone trabajar seis principios básicos, relacionados con la transformación social y cultural, la participación social en el centro educativo, espacios de comunicación dialógica, dialogo intercultural, emancipación crítica, autonomía personal así como un docente investigador y comprometido con el encargo social. En la figura 5 se explican cada uno de los principios anotados.

\section{Figura 5}

Principios básicos para la formación docente

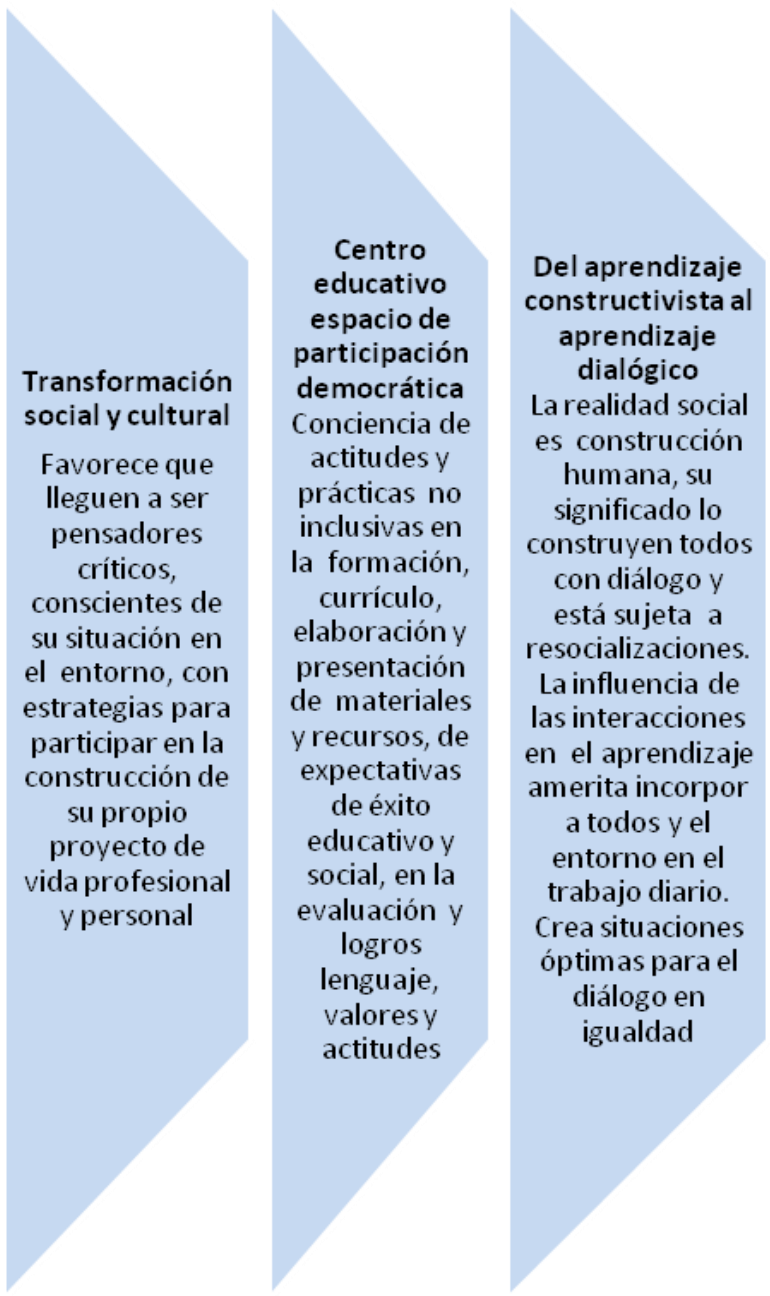

La búsqueda del diálogo intercultural El currículo, su lenguaje y organización deben

integrarlas perspectivas y aportaciones de los grupos y culturas de forma articulada mostrando quela sociedad evoluciona y se transforma gracias a la aportación de todos
Emancipación crítica y autonomía personal

Conceptualiza sociedad, educación cultura y como activas y dinámicas. Desde este supuesto el titulante construye su conocimiento crítica y

reflexivamente, saca sus propias conclusiones a partir de información y experiencia formativa
Docente como ciudadano e investigador comprometido Analiza, cuestiona y redefine su rol. Indaga con otrosagentes, identifica problemas educativos en relación con otros ámbitos, analiza en conjuntola causa de éstos, discute soluciones y se compromete en el cambio de actitudes y conductas insolidarias

Fuente: Elaboración propia a partir de Sales (2010).

El detalle de los principios anteriormente señalados comprende una perspectiva amplia que permite orientar la formación hacia un profesional comprometido, democrático, dialógico, con iniciativa y proactivo. 
De igual manera, Carro (2002) aporta otros principios en la formación del docente los cuales contribuyen a fomentar un perfil de profesional flexible, reflexivo, comprometido y motivado con su práctica, capacitado para tomar decisiones, basadas en un conocimiento profesional elaborado a partir del diálogo permanente entre teoría y práctica, los cuales se presentan en la figura 6.

\section{Figura 6}

Principios para la formación del profesorado

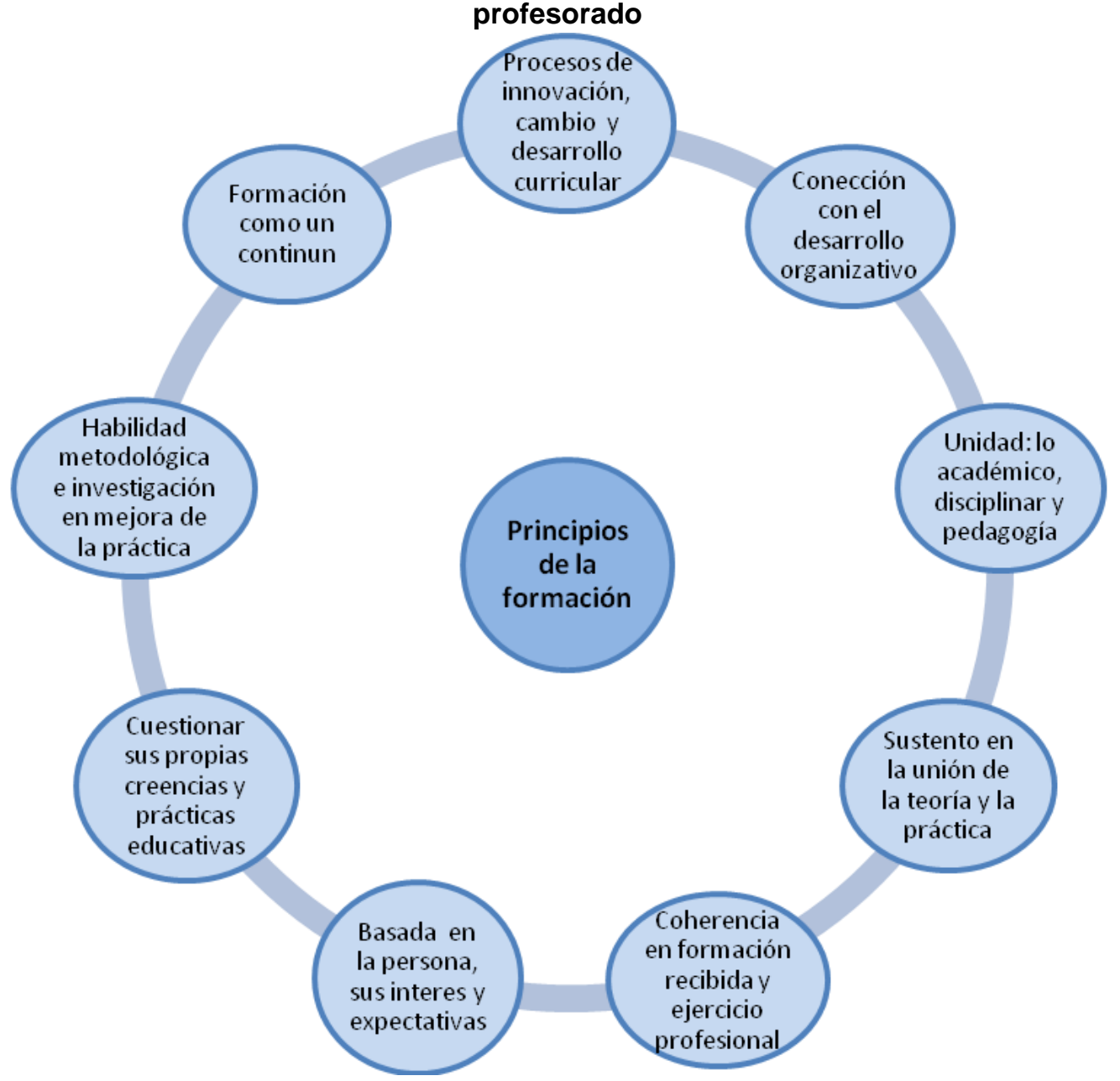

Fuente: Elaboración propia a partir de Carro (2002).

En ese sentido, los principios propuestos se centran en el desarrollo de competencias vinculadas con las diferencias particulares, con el hacer pedagógico e ideológico, lo organizacional, la unidad teórico práctica como fuente de enriquecimiento integral. En consecuencia, la formación docente debe orientarse hacia un profesional creativo con conocimientos claros sobre lo qué debe enseñar, cómo debe hacerlo y cuándo, por lo que se requiere que éste adquiera competencias en el manejo de estrategias de enseñanza y 
aprendizaje, manejo de la evaluación y comprensión del trabajo áulico a nivel individual y grupal (Gonzaga, 2005). Este mismo autor anota la necesidad de que el educador esté en capacidad de vencer las limitaciones y barreras que se le presenten en su práctica educativa para poder trascenderla, a través de la inventiva y la innovación. Desde la formación del docente hay que tener en cuenta su estilo de aprendizaje, su estilo de enseñanza y la interrelación de ambos a la hora de su actuación como docente.

Conjuntamente, Essomba (2006) y Arnaiz (2005) rescatan que educar al docente a partir de la educación inclusiva implica ejercer los principios de igualdad, desarrollo de estrategias personalizadas, promover la educación democrática, donde estén presentes los valores de la equidad, la solidaridad, la tolerancia, la cooperación y la convivencia, así como de un curriculum amplio, facilitando con ello el abordaje de la diversidad.

\section{2 Partir de la realidad y vincularse a la realidad}

Dentro de este contexto de optimización de la educación, y para avanzar hacia una formación docente con componentes de educación inclusiva, es fundamental partir del análisis de la realidad del entorno, esto permite conocer dónde se está y tener claridad hacia dónde se va, facilita implementar los ambientes adecuados de aprendizaje, se abren posibilidades de valorar los procesos que tienen lugar en el centro formativo y se refuerza con mayor convencimiento todo lo que de positivo se está produciendo en la práctica educativa de la formación profesional. Esta forma de trabajar formativamente conduce a preparar la transformación o modificar lo que falta.

Así, se van obteniendo mejores logros y se sigue avanzando y perfeccionando el proceso formativo con componentes de la educación inclusiva, ya que la formación parte de las condiciones particulares que la contienen, le dan sentido y explicación.

La buena práctica inclusiva debe entenderse como una actuación "situada", que adquiere sentido y es viable a partir de una realidad concreta, de unos condicionantes estructurales que la hacen única e irrepetible. No hay buenas prácticas ideales sino que dependen del contexto en el que se desarrollan. (Marchesi, Durán, Climent y Hernández, 2009, p. 5)

De ahí que sea de interés posicionarse dentro del modelo interaccionista donde el conocimiento se concibe como una forma de relación dialéctica con la realidad social y educativa, asumidas estas como situaciones históricamente situadas y encarnadas. Dicha 
perspectiva propone una ruptura entre la teoría y la práctica, entre el pensamiento y la acción, a partir del desarrollo y construcción del propio conocimiento, desde el quehacer educativo cotidiano, en el ejercicio diario de la práctica educativa. Así, el conocimiento se construye en la acción y a través de ella porque "conocer es actuar, actuar es conocer (Foerster, 1991, citado por Villegas y González, 2011, p. 5).

Esto significa que la persona, llámese estudiante, graduando, docente en formación, está implicada en la realidad del contexto sociocultural en el cual se produce el conocimiento y constituye la fuente en la que se engendra y se desarrolla el pensamiento. Supone por lo tanto, desplazamiento del pensamiento técnico teórico que predominó en la teoría curricular en los primeros setenta años del siglo XX hacia un pensamiento práctico-reflexivo presente en propuestas progresistas que buscan la transformación y articulación del quehacer educativo en todos sus niveles, aspecto que magistralmente se recoge a continuación:

Vivimos lazos y relaciones históricas, sociales y culturales que nos hacen sentirnos partícipes de unas señas de identidad colectivas. Nuestras culturas constituye el entramado de nuestros pensamientos, de nuestros sentimientos, de nuestros sueños, de nuestras formas de relación y de comunicación, de nuestra creatividad y la expresión de nuestro estar en el mundo. La cultura es aquello que asigna identidad a nuestra vida individual pero también a nuestra vida colectiva. (Marchesi, 2010, p. 1)

En ese sentido, asumir la formación docente, desde y por la educación inclusiva, es un desafío permanente, es apropiarse de un currículo como campo de estudio, de investigación constante y dinámico, de permanente realimentación con la realidad próxima y contextual con el propósito de ir estudiando la puesta en marcha del currículo y del modelo de formación que se quiere. Es pensamiento traducido en acción educativa con la intencionalidad manifiesta de incidir en la realidad circundante para llegar a mejores niveles de vida.

Los diversos autores que han trabajado la temática de la formación del docente puntualizan tomar en cuenta: lo intercultural con miras a la transformación social, cultural y sólida preparación profesional en cuanto a los criterios de diversidad.

En otro orden de cosas, se plantea que el docente debe tener conocimientos de la realidad en sus diferentes ámbitos; también, habilidades para aplicar diversas estrategias de intervención socioeducativa; habilidades para diseñar, adaptar y evaluar programas y finalmente, estrategias a implementar. 
Para que en el quehacer cotidiano educativo se construyan senderos que guíen hacia la educación para todos, se requiere transformar la realidad educativa, trabajar con parámetros inclusivos. El camino es dar al estudiantado en formación la oportunidad de tomar sus propias decisiones para ajustarse al contexto en el que interactúa. Lo anterior, conduce inevitablemente a asumir que no es posible contemplar propuestas de transformación en los centros educativos si estos no van acompañados de una buena formación, según se cuestiona en el siguiente texto transcrito:

¿A qué estamos esperando? ¿A qué se resuelve la crisis para disponer de mayores recursos? Creo que no, porque el movimiento de inclusión educativa comenzó cuando nos encontrábamos en el "estado del bienestar", al menos en Europa, y avanzó, pero con dificultades. Muchas de las opciones que hay que poner en práctica para que la educación inclusiva sea un hecho en las aulas, no suponen ningún incremento de recursos materiales. Otras sí, por supuesto. Pero la actitud favorable hacia la inclusión, la aceptación abierta de todo tipo de alumnado en el centro, la utilización variada de los recursos didácticos que ya están disponibles, la diversificación de métodos por parte del profesorado, la implementación del trabajo en grupo, colaborativo, entre los alumnos y alumnas dentro del aula, la adaptación del currículum a determinadas características del alumnado, la promoción de las familias en su compromiso con las actividades del centro docente..., estoy convencida de que son cuestiones que se pueden aplicar si hay se tiene voluntad de hacerlo y si se cuenta con la preparación profesional adecuada. (Casanova, 2011, p.48)

En este contexto, según la autora del texto anterior, no se pueden manifestar excusas para evitar la acción de caminar hacia la educación inclusiva, si las condiciones no están hay que irlas creando, si hay obstáculos hay que removerlos desde la acción y no solo desde el discurso o la queja. Caminar hacia la educación inclusiva es compromiso hecho acción y acción con compromiso de construir un mundo, una sociedad más inclusiva, es consolidar una cultura educativa de mejoramiento continuo por medio de procesos de autoevaluación y evaluación que permitan estimar y medir el impacto de la pertinencia e impacto de la formación y llegar así, a la planificación y al desarrollo de currículos inclusivos de calidad, excelencia y pertinencia. 


\subsection{Resignificación de la práctica educativa}

Este aspecto se orienta a darle un sentido dinámico a la práctica educativa para mejorar e enriquecer el quehacer educativo desde la perspectiva de que la naturaleza de la práctica educativa es una situación singular, dinámica, heterogénea, fundamentada en valores e incierta como toda praxis social, es decir como un proceso único y en continua construcción, como se indica en la figura 7:

Figura 7

Naturaleza de la práctica educativa

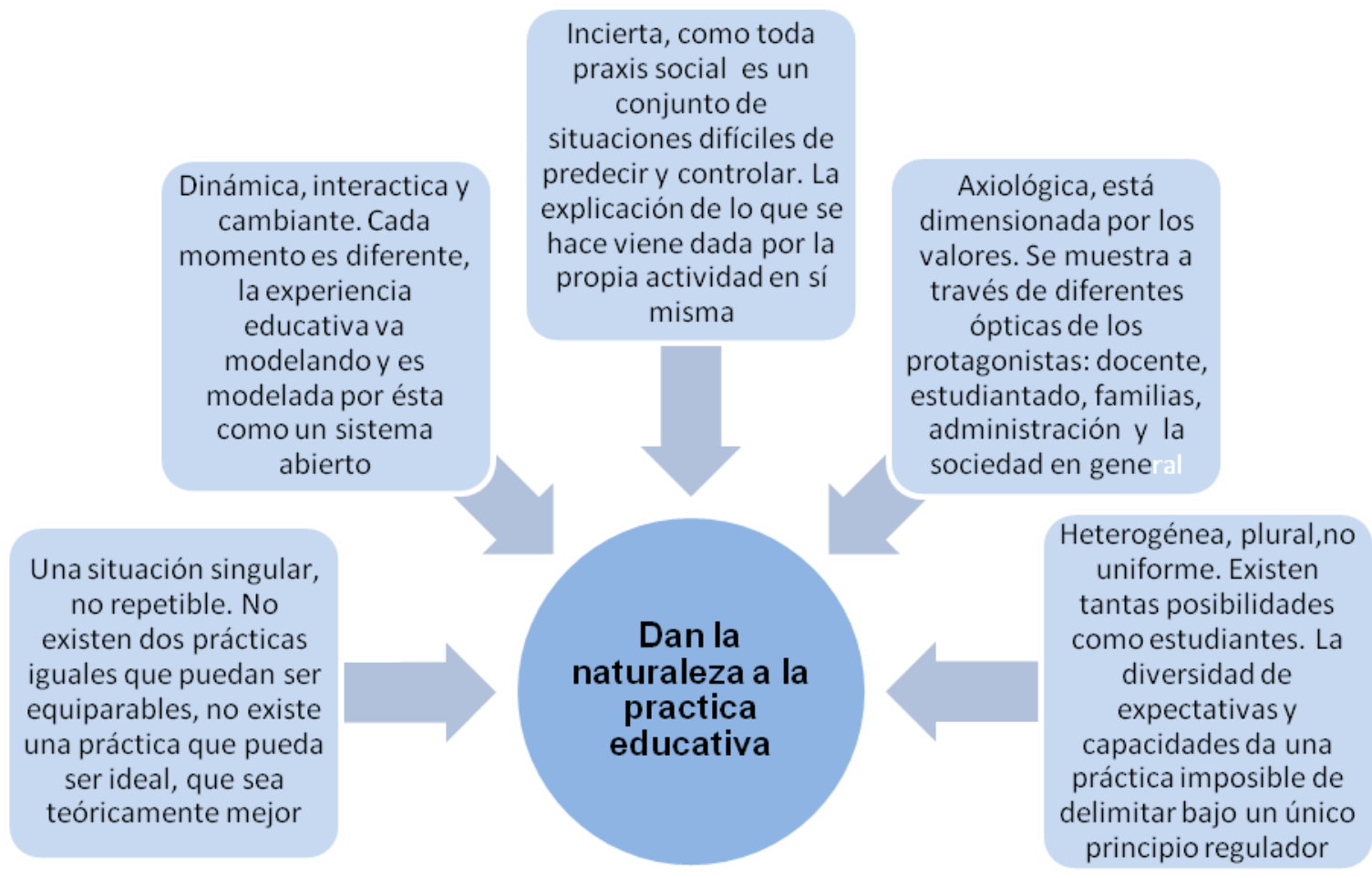

Fuente: Elaboración propia a partir de Carro (2002).

De acuerdo con la información de la figura anterior, la práctica cotidiana es el sustento de los cambios sociales y educativos que se quieren lograr. En este espacio pedagógico y próximo se inician y generan los pequeños cambios que, posteriormente, se extrapolarán al sistema educativo y a la sociedad en su conjunto; es decir, es en la vida diaria donde se suceden las transformaciones cualitativas que desde la cotidianidad, al ser sopesadas y 
revalorizadas, adquieren nuevos significativos en el quehacer educativo, porque permiten vislumbrar el horizonte, tomando en cuenta múltiples senderos, como el enfoque de derechos, el respeto y valoración de lo diverso, la convivencia entre unos y otros, la singularidad y lo diferente. Esta orientación en el quehacer formativo docente es un modo seguro de caminar hacia una educación inclusiva, la cual busca la creación de espacios educativos democráticos y de excelente calidad, donde los estudiantes serán los protagonistas de asumir la responsabilidad educativa.

\subsection{Promover más procesos reflexivos}

A partir de la asunción de una educación inclusiva en la formación docente se hace posible la renovación continua de la educación, conducente a reflexionar sobre las competencias necesarias para atender la diversidad del estudiantado, desde la articulación de la teoría y la práctica. Así la reflexión es un proceso complejo y crítico, según se desprende del siguiente texto transcrito:

La transformación de determinado material primitivo de nuestra experiencia (ofrecido desde la historia y la cultura y mediado por las situaciones que vivimos) en determinados productos (pensamientos comprensivos, compromisos, acciones), una transformación afectada por nuestra concreta tarea (nuestro pensamiento sobre las relaciones entre el pensamiento y la acción, y las relaciones entre el individuo y la sociedad), utilizando determinados medios de producción (comunicación, toma de decisiones y acción). (Kemmis, 1985, citado por Palomares, 2004, p. 103)

Justamente, la preparación de docentes debe construir una nueva manera de acercarse a la realidad, de conocerla, de cuestionarla pues el modelo tradicional de formación, en respuesta a cuestiones meramente academicistas e instrumentales, no satisface las demandas de forma integral de la realidad cambiante, incierta y plural. Al respecto, Lugo y Padrino (2012) citan a Morin para indicar que si se cambia la forma de llevar a cabo la formación docente podrían hacerse efectivas las grandes finalidades educativas: crear cabezas bien puestas más que bien llenas, enseñar la condición humana, afrontar la incertidumbre, enseñar a transformarse y a autoformarse porque para ser un buen profesional de la educación no basta con tener mucha información, que no le es útil ni pertinente en su práctica educativa. 
Es importante destacar que cuando Morin menciona la necesidad de organizar el pensamiento, el conocimiento, se refiere no solo al especializado, al académico sino al conocimiento en general en sus más variadas fuentes, al conocimiento que nos acompaña y que se produce en el diario vivir. De vital importancia es pensar el futuro con incertidumbre como una vía para comprenderlo y asumirlo. De esta manera podremos construir una sociedad planetaria donde el ser humano sea actor y autor de su propio destino, esculpiendo una mejor calidad de vida para todos y dejando un mejor mundo para las generaciones venideras. (Lugo y Padrino, 2012, p. 1)

Tomando en cuenta el planteamiento anterior, es necesario, desde los procesos reflexivos, propiciar e impulsar nuevos senderos para construir una realidad educativa intercultural y diversa que permita una nueva manera de aprehender y comprender la realidad, de posesionarse y proyectarse. Por eso, en los planes de estudio se deben incorporar espacios de formación en todos los cursos y prácticas estudiantiles como parte de la estructura curricular, que conduzcan el logro de un perfil profesional tendiente a alcanzar docentes reflexivos, capaces de cuestionarse su propia práctica educativa desde su proceso formativo, de buscar y poner en ejecución respuestas colaborativas e interrelacionadas con el entorno circundante, además de asumir el compromiso de su quehacer educativo, como persona y profesional de la educación. Esto supone que el personal docente de la unidad formadora asuma estos procesos en el desarrollo de sus asignaturas y demás actividades universitarias.

\subsection{Formación docente en congruencia con modelos democráticos}

Como un elemento trascendental se incorpora la formación democrática del docente para hacer realidad procesos educativos democráticos y en sus entornos. Una educación de corte democrático, como lo plantea la educación inclusiva, implica congruencia en la formación y en la forma como se ejerce la función docente. Construir modelos educativos democráticos e inclusivos requiere docentes democráticos e inclusivos. El formar un docente en congruencia con modelos democráticos implica apostar a:

una persona comprometida con la construcción de la democracia como horizonte político-social, consciente de la importancia de relacionar la escuela con la vida y de promover una intensa red de relaciones intra e interinstitucionales. El docente democrático está llamado a formarse permanentemente en asociación con otros para 
hacer del trabajo escolar un esfuerzo corresponsable que le exigirá un alto grado de disciplina intelectual, cívica y política cónsona con su responsabilidad social. Su compromiso democrático se traduce en una actitud ética de respeto a la persona del alumno y una atención a sus preocupaciones e intereses. (Muñoz, 2006, p.191)

De tal manera, formar un docente en congruencia con modelos democráticos desarrolla características como las que se muestran en la figura 8:

\section{Figura 8}

\section{Características de un docente democrático}
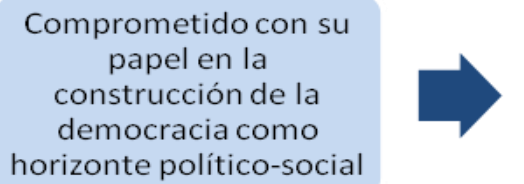

Consciente de la importancia de la vida, de la realidad, en su quehacer cotidiano

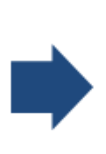

Asume la disciplina cívica y política en consonancia con su responsabilidad social
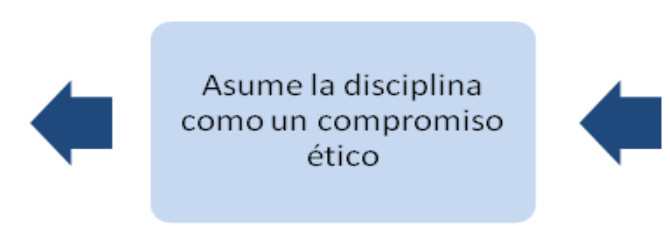

Promotor de una escuela rica en relaciones

interpersonales, abierta al entorno

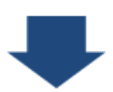

Formación permanente, en diálogo con otros docentes, para dar respuestas a educativas compleja y vinculada a la incertidumbre

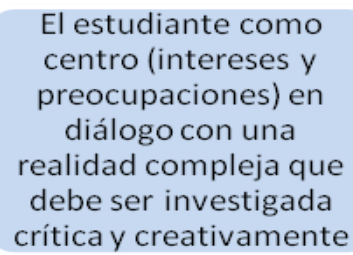

Fuente: Elaboración propia a partir de Muñoz (2006).

En ese mismo sentido, formar un docente democrático supone, entre otras medidas, una adecuada formación del profesorado en los principios básicos de atención a la diversidad y promover la colaboración entre docentes, ya que éstos deben asumir nuevos roles al tener que responsabilizarse de toda la población estudiantil en la planificación e implementación del curriculum y mantener relaciones de cooperación. 


\subsection{Preparado para generar redes de colaboración y comunicación}

El desarrollo de capacidades docentes conlleva generar y sostener redes de trabajo que sobrepasen las fronteras del centro educativo para comentar, intercambiar y apoyar propuestas inclusivas para mejorar la acción, para hacer frente a las tareas y decisiones complejas y éticamente controvertidas.

De igual manera, Echeita (2004) anota la necesidad de que el docente esté preparado para organizar redes de apoyo con diferentes actores sociales y comunales con el fin de contribuir a resolver problemas y conflictos del ámbito educativo. Esta red vendría a ser un punto de apoyo en la labor docente y le aportaría mayor seguridad.

Mediante el desarrollo de habilidades para la construcción de redes de colaboración y comunicación en su proceso formativo, el profesorado contará con las condiciones para impulsar estrategias de trabajo cooperativo, a través de vínculos esenciales de participación y de apoyo mutuo con los diferentes actores sociales.

Se debe elaborar un marco coherente de gestión educativa que favorezca un cambio sustancial del sistema, lo cual es indispensable en la formación de docentes con perfil inclusivo, donde la simplificación y la flexibilización de la gestión educativa sean eficientes y eficaces para responder a las demandas y necesidades del entorno y de la sociedad costarricense.

La meta de la educación inclusiva es la de ampliar el acceso a la educación y promover la participación justa y equitativa de todo el estudiantado, a partir de sus diferentes capacidades. Por lo tanto, se hace necesaria la formación de competencias para crear, conducir y administrar equipos directivos en el desarrollo de sus habilidades de liderazgo y perspectivas en consonancia con los valores y la práctica inclusivos.

Esto significa que los profesionales en educación deben ser formados para trabajar en entornos variados e inclusivos, tanto en la formación inicial como en la continua para desarrollar el conocimiento y las competencias que propicien su modo de afrontar la diversidad en los centros inclusivos. La educación inclusiva demanda profesionales reflexivos, capaces de tomar decisiones para adaptar sus aulas a las necesidades del estudiante. Sin embargo, los sistemas tradicionales siguen vigentes, generando así, barreras para el desarrollo de la educación inclusiva.

Es por eso que la formación docente inclusiva precisa lo que, magistralmente, Giroux (1997) denomina profesores como intelectuales transformativos. Entendiéndose por intelectual transformativo aquel: 
docente que analiza su práctica con el fin de crear espacios donde todos y todas tengan las mismas posibilidades, tanto dentro de la escuela como cuando salgan de ella. Es un profesional comprometido con la lucha por una escuela sin exclusiones. (Almenta y Leiva, 2012, p. 912)

\subsection{Autonomía en la formación docente}

Se deben formar profesionales capaces de actuar, de crear, de renovar y visualizar para aceptar cambios a favor de sujetos reflexivos, innovadores, eficaces y críticos; focalizando prioridades educativas. Así, "la formación adecuada es una exigencia para llevar a buen término el modelo de educación inclusiva" (Casanova, 2011, p. 94).

En ese sentido, hablar de formación docente, es hacer énfasis en autonomía, entendida esta como el desarrollo de la capacidad para pensar, reflexionar y decidir el devenir de la acción educativa de forma planificada desde la gestión y administración educativa (Casanova, 2011). Esta es la planificación requerida como herramienta de formación del profesorado; por tanto, no puede desarrollarse ajena al espacio propicio para una auténtica autonomía.

Tomando en cuenta lo anterior, un docente, en el ámbito de la educación inclusiva, necesita conocer la naturaleza de la cultura en la que está inserto, ser consciente de lo que significa una escuela inclusiva, ser crítico, autónomo y responsable, saber analizar, y con base en estas capacidades poder decidir.

De hecho, Pérez (2008) parte del supuesto de que la formación del pensamiento práctico, o teoría sobre la práctica del futuro profesor, debe de desarrollarse a través de un proceso dialéctico de construcción y reconstrucción del conocimiento pedagógico vulgar que se adquiere a través de la experiencia como estudiante. El paso por el sistema educativo tradicional hace que la persona asuma acríticamente las estrategias metodológicas presenciadas, y la forma de cuestionar estas concepciones es contrastarlas con el conocimiento científico, para que se produzca el conflicto cognitivo necesario para la formación.

Un docente con vacíos en su formación no estará en condiciones de asumir la responsabilidad que supone tomar decisiones sobre la acción educativa. Tampoco, podrá valorar a posteriori la conveniencia de dichas decisiones para mejorarlas, es decir, un educador formado con estas características, difícilmente, contará con los recursos formativos para incidir en la transformación requerida. Formación y autonomía van de la mano (Almenta 
y Muñoz, 2007). Por eso, es menester el desarrollo de currículos basados en el desarrollo de las competencias mediante el emprendedurismo, la creatividad, la innovación y la independencia.

\subsection{Manejo de las tecnologías de la información y comunicación}

En la era del conocimiento y de las tecnologías se hace necesario proponer, dentro de estos lineamientos, que el profesorado sea capaz de acceder y manejar exitosamente las tecnologías de la información y comunicación, las cuales deberán incorporarse plenamente en el proceso educativo. En ese sentido, se deben integrar los sistemas de información, así como fortalecer la formación digital para una mayor eficacia y eficiencia de la gestión educativa. De igual manera, el proceso formativo debe apoyarse en el desarrollo de habilidades y actitudes hacia el desarrollo de un profesional que aprende a lo largo de su vida, por diferentes medios y experiencias, porque cada situación es vislumbrada como una oportunidad de aprender y potenciar sus capacidades. Se trata, entonces, de formar a un profesorado en permanente actualización, perfeccionamiento y renovación.

\subsection{Preparado para trabajar con y desde la diversidad}

Este es un componente que conlleva a la adquisición de los conocimientos, actitudes y competencias para diferenciar y dar respuesta a la diversidad de necesidades que permitan al docente la atención personalizada dentro y fuera del aula. Supone formar a cada estudiante en la toma de decisiones de su propio aprendizaje y en su compromiso de construir centros inclusivos como espacio de convivencia y encuentro con la diversidad.

El abordaje de la educación inclusiva remite necesariamente a tratar el componente de diversidad, por ser esta consustancial entre los seres humanos. En este sentido, la diversidad debe ser considerada como un valor que reconoce las diferencias y respeta la individualidad de cada persona, desde la valoración, aceptación y el reconocimiento del otro. Estas diferencias aportan al mundo lo que cada persona es, sin importar lo que le hace falta respecto de la norma. Asimismo, le dan relevancia a lo que se tiene y lo que se es, con lo cual enriquecen a las demás personas de manera individual y grupal.

La diferencia se debe concebir como un elemento de riqueza de la colectividad, y no como un elemento de exclusión. En este contexto se requiere de docentes preparados para trabajar con y desde la diversidad, fortalecer el manejo de metodologías y estrategias de inclusión, las cuales pueden ser: el aprendizaje cooperativo, las tutorías de iguales, el diseño 
multinivel, la flexibilización de tiempos y espacios, ciertas estrategias eficaces para el desarrollo de actitudes positivas y por último, la garantía de que los docentes se consideren capaces de asumir la responsabilidad de dar respuesta a la diversidad estudiantil, independientemente de sus necesidades (Blanco, 2000).

\subsection{Desarrollo personal y profesional permanente}

La formación es un proceso de enseñanza aprendizaje, y los docentes deben asumir la responsabilidad de su aprendizaje permanente. Es importante dentro de estos lineamientos formar un docente que sea capaz de considerar el aprendizaje como un proceso, basado no solo en los contenidos y conocimiento de asignaturas, sino también, en el desarrollo de las competencias de aprender y reaprender y, con ello contribuir a dar una formación más significativa.

Hemos de ser innovadores y mirar hacia el futuro. Hemos de apostar en nuestro esfuerzo colectivo por abrir nuevos caminos en la educación. Sin duda, el logro de las competencias matemáticas, lingüísticas y científicas ha de estar en el centro del quehacer educativo. Pero no podemos olvidar el papel de las artes, de la música, de la cultura, del deporte, de la lectura, de las nuevas tecnologías para la construcción de una ciudadanía multicultural en la que tan importante es aprender a conocer como a aprender a convivir, aprender a sentir y a conmoverse, aprender a ser solidario, justo, leal y honesto.

Como afirmó con acierto José Martí, ser bueno es el único modo de ser dichoso. Ser culto es el único modo de ser libre. Esa es la tarea de la educación, de las escuelas, de los maestros: formar mujeres y hombres buenos, felices, cultos y libres. No sólo unos pocos, sino todos, sin excepción, sin exclusión. (Marchesi, 2010, p.3)

En el fortalecimiento del desarrollo personal y permanente es importante el afianzamiento de varias dimensiones entrelazadas para posicionarse integralmente en la tarea y reto educativo por asumir (Agencia Europea para el Desarrollo de la Educación del Alumnado con Necesidades Educativas Especiales, 2011). Dichas dimensiones son las siguientes:

- La dimensión cognitiva orientada al saber en términos de conocimientos científicos, metodológicos, instrumentales. 
- La dimensión técnica para aplicar los saberes de manera pedagógica, instrumental y metodológica.

- La dimensión social y económica para comprender y situarse en la realidad a través del desarrollo de las habilidades e interacciones sociales y del medio.

- La dimensión ética que comprende el saber y deber ser del profesional, desde los valores, así como las regulaciones, principios y normas que regulan el ejercicio profesional.

Estas dimensiones formativas tendrán una influencia en la forma como el docente ejerza su labor y en las relaciones que establezca en el centro educativo, en el aula, en la comunidad y con los diferentes agentes educativos. Consecuentemente, le brindará herramientas valiosas para su desempeño debido a que:

Es el tiempo de la esperanza, del esfuerzo, de la solidaridad, del compromiso colectivo. Ustedes, sí, son la mayor riqueza de la región. No hay más calidad en la educación que la calidad de sus maestros y por ello el proyecto se propone cuidar especialmente las condiciones laborales, sociales y pedagógicas del trabajo del profesorado. Maestros y maestras: son ustedes la esperanza de los sueños iberoamericanos. En ustedes reposa nuestra confianza en el futuro de nuestros países. Son ustedes la principal riqueza de la región. No se cansen. A pesar de sus dificultades, a pesar de sus difíciles condiciones de trabajo, a veces heroicas, mantengan su esfuerzo y su compromiso. En su dedicación está en gran medida la garantía del éxito de este proyecto. (Marchesi, 2010, p. 3)

A partir de estos planteamientos se integran, en la figura 9, diferentes niveles complementarios, articulados e integrados entre sí, los cuales contemplan los diversos lineamientos de ser trabajados en los procesos formativos del docente, para dar respuestas de calidad en la atención diversidad imperante en la sociedad actual. 
Figura 9

Lineamientos prospectivos de educación inclusiva en la formación docente

Dimensión ideológica, política y ética de procesos de planificación

desarrollo y evaluación de prácticas inclusivas

\section{Tecnologías de la información y comunicación}

\section{Diversidad}

rabajo en equipos

diversos y redes
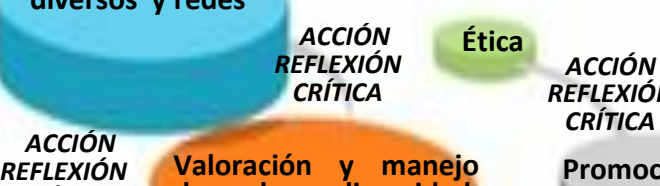

Práctica democrática de educación inclusiva

Curriculum

flexible

CRÍTICA de la diversidad

Promoción de la

CRÍTICA de la diver

pluriculturalidad

ACCIÓN

REFLEXIÓN

CRÍTICA

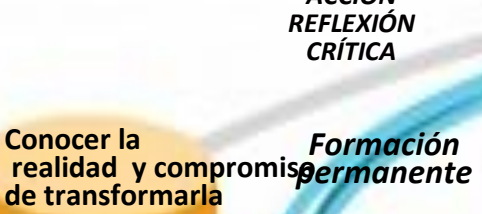

Idónedransformación

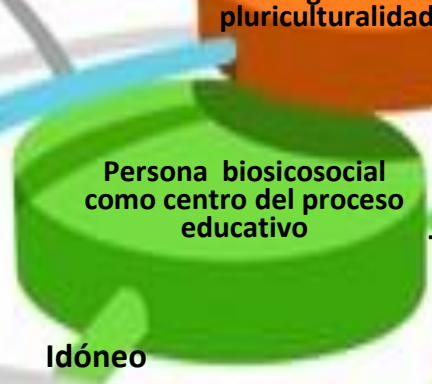

Transformación

participación

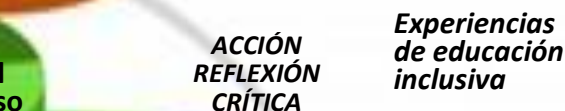

de transformarla CRITICA

de educación

inclusiva

\section{Transformación}

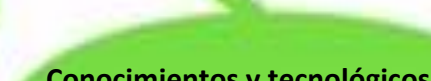
actitudes, valores, gestión y manejo de recursos, comprensión de la inclusión, la innovación y el cambio

Formación del profesorado en Educación Inclusiva:

formación y autonomía para actuar, profesionalizar, crear, renovar, permitir y visualizar

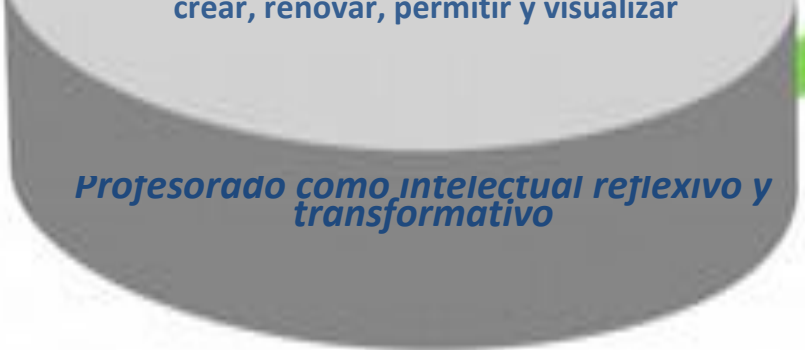

Idóneo
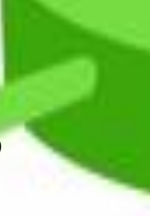

Marco legal normativa oficial educativa: posibilidades y limitaciones

\begin{abstract}
Proceso formativo vivencial de modelos de enseñanza autónoma y de responsabilidad reflexiva, conectando los aprendizajes teóricos y prácticos a través de la réflexión, con conciencia de las teorías que aplica y confrontando lo que podría hacer con su posición ideológica
\end{abstract}

Fuente: Elaboración propia a partir del procesamiento de la información documental

Los lineamientos descritos en los párrafos anteriores pretenden brindar insumos que faciliten la transformación del proceso formativo y que generen espacios reflexivos, de tal manera que conduzcan a la deliberación de que: 
conseguir personas preparadas para la tarea de educar en la inclusión se convierte en una emocionante aventura que requiere una concepción diferente de la simple transmisión de conocimientos técnicos. Requiere una actitud, un espíritu inquieto y un "saber hacer" basado en la reflexividad. El profesorado que reflexiona sobre lo que hace se convierte en investigador de su práctica en la medida que cualquier decisión docente es considerada provisional y que responde a las necesidades del momento en el que esa decisión fue tomada". (Carro, 2002, p. 3)

Es decir, es una apuesta por concebir el proceso formativo desde una mirada diferente, no como algo acabado, sino en constante construcción y con capacidades para enfrentar la incertidumbre, el cambio y la permanente auto-capacitación y actualización.

\section{Conclusión}

Sin lugar a dudas, se vive en un mundo en permanente cambio, matizado por la duda y la incertidumbre que pone en constante interrogante la calidad del quehacer educativo. Los procesos de transformación educativa que hace unas décadas tendían a perdurar durante años se suceden ahora vertiginosamente. Lo que hoy es novedoso, mañana resulta anticuado. Se está ante un nuevo mapa político, social, cultural y educativo que se dibuja como inestable por su naturaleza altamente variable. La educación, como sistema integrante de la sociedad y reflejo de ella, no puede permanecer ajena al cambio de escenario y está obligada a renovarse para dar respuesta a los desafíos que la sociedad del siglo XXI está experimentando.

Por otro lado, las demandas de la sociedad exigen una mayor preparación académica, más integral y humana para afrontar una realidad cada vez más compleja. Las unidades formadoras experimentan grandes desafíos para responder a dicha complejidad y dar respuestas de calidad en la formación de un docente reflexivo y respetuoso de la diversidad.

De esta manera, la formación del docente es uno de los retos que afronta la educación actual, por ser este uno de los artífices del proceso educativo. En su proceso formativo el docente debe estar preparado en los ámbitos pedagógicos, psicológicos e ideológicos para atender la diversidad, construir diferentes escenarios de aprendizaje y garantizar una educación con componentes de educación inclusiva y de calidad.

En este sentido, las unidades de formación docente como entes académicos perciben que asumir el compromiso con la educación inclusiva constituye una oportunidad para aprender a hacer la tarea educativa de formas diferentes a las tradicionales. Resulta que 
para alcanzar ese momento es preciso comenzar a realizar las acciones necesarias de perfeccionamiento de la calidad educativa. Es una buena forma de indagar, sobre una base de evaluación certera de las diversas situaciones, condiciones, necesidades y, recursos de todo tipo pendientes de alcanzar para seguir avanzando hacia el logro de una educación más inclusiva.

Avanzar hacia un modelo de educación inclusiva requiere partir de la realidad del entorno, tener claro hacia dónde se orienta la educación, implementar ambientes adecuados y valorar los procesos formativos. Asimismo, es necesario analizar las estructuras organizacionales para fortalecer lo positivo de la práctica educativa en la formación profesional; optimizar la capacidad instalada, además, identificar barreras, así como transformar los obstáculos en oportunidades para perfeccionar el proceso formativo del docente.

La formación de profesionales es una perspectiva segura que busca la creación de espacios educativos democráticos y de calidad para atender a todos y a cada uno de los estudiantes, quienes serán los protagonistas en la formación de futuros educandos.

El asumir la educación inclusiva en la formación del docente hace posible el remozar constantemente, la educación, una enseñanza que conduzca a reflexionar sobre las competencias necesarias para atender las diferentes capacidades del estudiantado. Para ello, es necesario articular teoría y práctica a través de la reflexión de las teorías que se aplican y de la confrontación de posiciones ideológicas examinando lo que podría hacer con su posición ideológica. Para avanzar hacia la consolidación de una educación inclusiva desde la formación del docente, se requiere propiciar espacios reflexivos que amplíen la percepción de lo que significa educar, en y para, la diversidad en el contexto actual.

Finalmente, la educación inclusiva como elemento indiscutible en la formación docente se constituye en una herramienta necesaria para atender la diversidad, como principio básico para lograr oportunidad e igualdad para todos, es decir, una educación de calidad, una educación democrática. 


\section{Referencias}

Agencia Europea para el Desarrollo de la Educación del Alumnado con Necesidades Educativas Especiales. (2011). Formación del profesorado para la educación inclusiva en Europa - Retos y oportunidades. Odense, Dinamarca: Autor.

Ainscow, Mel, Booth, Tony y Dyson, Alan. (2006). Mejorando las escuelas, desarrollando inclusión. Londres: Routledge.

Ainscow, Mel. (2001). Desarrollo de escuelas inclusivas. Ideas, propuestas y experiencias para mejorar las instituciones escolares. Madrid, Narcea.

Almenta, Estefanía y Leiva, Juan. (2012). Formación Inicial del Profesorado para una Escuela Inclusiva: el Aprendizaje Profesional de los Estudiantes del Grado de Educación Primaria. En Manuel J. Cotrina García y Mayka García (coord.), Prácticas en Educación inclusiva: diálogos entre Escuela, Ciudadanía y Universidad (pp. 908916). Cádiz: Universidad de Cádiz.

Almenta, Estefanía y Muñoz, Juana. (2007). ¿Estamos formados para trabajar en una escuela inclusiva? En Actas del V Congreso Internacional Educación y Sociedad. La educación, retos del siglo XXI. Granada: Codoli.

Arnaiz, Pilar. (2003). Educación inclusiva: una escuela para todos. Málaga: Editorial Aljibe.

Arnaiz, Pilar. (2005). Atención a la diversidad. Programación curricular. San José: Editorial Universidad Estatal a Distancia (EUNED).

Barnett, Lew. (2003). El aprendizaje cooperativo y las estrategias sociales. En Lew Barnett et al., Motivación, tratamiento de la diversidad y rendimiento académico. El aprendizaje cooperativo (pp. 117-124). Barcelona: GRAÓ.

Blanco, Rosa. (2000). La atención a la diversidad en el aula y las adaptaciones del currículo. En César Coll (comp.), Desarrollo psicológico y educación (Vol. 3 Trastornos del desarrollo y necesidades educativas especiales, pp. 411-438). Madrid, España: Editorial Alianza Psicología.

Blanco, Rosa. (2010). El derecho a la educación. Presentación. Revista Latinoamericana de Educación inclusiva, 4(2), 15-22. Escuela de Educación Diferencial Facultad de Ciencias de la Educación Universidad Central de Chile.

Blat, José y Marín, Ricardo. (1980). La formación del profesorado de educación primaria y secundaria. Estudio comparativo internacional. Barcelona: Teide/ UNESCO.

Booth, Tony. (2006). Manteniendo el futuro con vida, Convirtiendo los valores de la inclusión en acciones. En Miguel Ángel. Verdugo y F.B. Jordán Urrías (Coords.), Rompiendo Inercias: claves para avanzar. VI Jornadas científicas de Investigación sobre personas con discapacidad (pp. 211-217). Salamanca, España: Amarú.

Carro, Luis. (2002). Inclusión: formación del profesorado. Recuperado de http://www.luiscarro.es/inclusion/Formacion Profesorado/profesorado.htm 
Casanova, María Antonia. (2011). Educación inclusiva: un modelo de futuro. España: Wolters Kluwer.

Confederación Española de Organizaciones a favor de las Personas con Discapacidad Intelectual. (2009). La Educación que queremos. Situación actual de la Inclusión Educativa en España. Recuperado de http://www.feaps.org/archivo/publicacionesfeaps/libros/coleccion-feaps/297-la-\%20educacion-que-queremos-situacion-actual-dela-inclusion-educativa-en-

Costa Rica, Asamblea Legislativa. (1949). Constitución Política de la República de Costa Rica. San José, Costa Rica: Publicaciones Jurídicas.

Costa Rica, Asamblea Legislativa. (1957). Ley Fundamental de Educación. San José: Asamblea Legislativa.

Costa Rica, Asamblea Legislativa. (1998). Ley 7600 Igualdad de oportunidades para las personas con discapacidad. San José, Costa Rica: Imprenta Nacional.

Costa Rica, Asamblea Legislativa. (2008). Ley 8861 Convención sobre los Derechos de las Personas con Discapacidad y su Protocolo Facultativo. San José, Costa Rica.

Costa Rica. Ministerio de la Presidencia. (2011). Política Nacional en Discapacidad 20112021 (PONADIS). Recuperado de http://www.asamblea.go.cr/Centro de informacion/biblioteca/Centro Dudas/Lists/Form ule\%20su\%20pregunta/Attachments/1295/Decreto\%2036524.pdf

Doré, Robert, Wagner, Sergie y Brunet, Jean- Pierre. (2002). Integración Escolar. México: Pearson Educación.

Echeíta, Gerardo y Simón, Cecilia. (2007). Educación para la inclusión. Educación sin exclusiones. Madrid: Narcea.

Echeíta, Gerardo y Simón, Cecilia. (2007). La contribución de la educación escolar a la calidad de vida de las personas con discapacidad. Ante el desafío de su inclusión social. En Rafael de Lorenzo García y Luis Cayo Pérez Bueno (Dirs.), Tratado sobre discapacidad (pp. 1103-1133). Navarra: Aranzadi.

Echeíta, Gerardo y Verdugo, Miguel Ángel. (2004). La declaración de Salamanca sobre necesidades educativas especiales 10 años después: Valoración y prospectiva. Salamanca: INICO. Recuperado de http://sid.usal.es/idocs/F8/FD09045/declaracion salamanca completo.pdf

Echeíta, Gerardo. (2003). Sentir el apoyo de los compañeros. Las estrategias de aprendizaje cooperativo. En Lew Barnett et al., Motivación, tratamiento de la diversidad y rendimiento académico. El aprendizaje cooperativo (pp. 33-38). Barcelona: GRAÓ.

Echeíta, Gerardo. (2004). ¿Por qué Jorge no puede ir a la misma escuela que su hermano? Un análisis de algunas barreras que limitan el avance hacia una escuela para todos y con todos. Revista REICE, 2(2), 30-42. 
Echeíta, Gerardo. (2006) Educación para la inclusión. Educación sin exclusiones Madrid: Narcea.

Echeíta, Gerardo. (2010). Alejandra L. S. o el dilema de la inclusión educativa en España. En Pilar. Arnaiz, María Dolores. Hurtado y F. J. Soto (Coords.), 25 años de Integración Escolar en España. Tecnologías e inclusión en el ámbito educativo, laboral y comunitario (pp. 1- 13) Murcia: Consejería de Educación, Formación y Empleo.

Essomba, Miguel Ángel. (2006). Liderar escuelas interculturales e inclusivas. GRAÓ: Barcelona.

Esteve, Francesc, Ruiz, Oscar, Tena, Sergio y Úbeda, Iván. (2006). La Escuela Inclusiva. Recuperado de http://www.uji.es/bin/publ/edicions/ifi11/9.pdf

Forteza, Dolors. (2010). La formación del profesorado en y para la educación inclusiva desde la perspectiva de la convergencia europea. Recuperado de http://www.centrodocumentaciondown.com/uploads/documentos/36b7c169f84273904d 06ad1eac3523b10aed83f9.pdf

García, Carmen. (2005). Educación y diversidad. Málaga: Aljibe.

García, Carmen. (2008). A propósito de la diversidad: pensar la propia diferencia y educar en relación. Kikirikí. Cooperación Educativa, (89), 22-29.

Giroux, Henry. (1997). Los profesores como intelectuales. Hacia una pedagogía crítica del aprendizaje. Barcelona: Paidós/ M.E.C.

Gonzaga, Wilfredo. (2005). Las Estrategias Didácticas en la Formación de Docentes de Educación Primaria. Actualidades Investigativas en Educación, 5(1). DOI: http://dx.doi.org/10.15517/aie.v5i1.9115

González, Flor. (2008). Escuelas inclusivas: una esperanza para el mundo actual. Documento incluido en el sitio Movimiento de inclusión en educación. Recuperado de https://florgonzalez.wordpress.com/2008/09/

Lugo, José Aquiles y Padrino, Feryeny. (2012). Análisis del libro Con la cabeza bien puesta de Edgar Morin. Recuperado de http://aquileslugo.blogspot.com/2012/05/analisis-dellibro-con-la-cabeza-bien.html

Marchesi, Álvaro. (2010). Palabras del Secretario General de la OEI en la inauguración del Congreso Iberoamericano de Educación. Metas 2021. Recuperado de http://www.metas2021.org/congreso/inauguracion marchesi.htm

Marchesi, Álvaro, Durán, David, Climent, Giné y Hernández, Luis. (2009). Guía para la reflexión y valoración de prácticas inclusivas. Recuperado de http://www.oei.es/inclusivamapfre/Guia.pdf

Muñoz, Diego. (2006). Docente democrático en pedagogos del siglo XX. Sapiens. Revista Universitaria de Investigación, 7(2), 191-213. 
Organización de Naciones Unidas para la Ciencia y la Cultura. (2008). La Educación inclusiva: El camino hacia el futuro. Documento presentado a la Conferencia Internacional de Educación. Ginebra, UNESCO. Recuperado de http://www.ibe.unesco.org/fileadmin/user upload/Policy Dialogue/48th ICE/ICE FINAL REPORT spa.pdf

Organización de Naciones Unidas. (2006). Convención sobre los Derechos de las Personas con Discapacidad. Recuperado de http://www.un.org/esa/socdev/enable/documents/tccconvs.pdf

Organización de Naciones Unidas. (1990). Declaración Mundial sobre educación para todos "Satisfacción de las necesidades básicas de aprendizaje. Recuperado de http://www.oei.es/efa2000jomtien.htm

Palomares, Ascensión. (2004). Profesorado y educación para la diversidad en el siglo XXI. Cuenca: Universidad de Castilla, La Mancha.

Parrilla, Ángeles. (2002). Acerca del origen y sentido de la educación inclusiva. Revista de Educación, (327), 11-29.

Pérez, Francisco. (2008). La escuela inclusiva y los procesos de formación del profesorado. Recuperado http://www.juntadeandalucia.es/educacion/portal/com/bin/Contenidos/IEFP/Publicacion es/PERSPECTIVA CEP/1226481372203 06 colab inclu.pdf

Sales, Ma. Auxiliadora. (2010). La formación intercultural inclusiva del profesorado: Hacia la transformación social. Revista Latinoamericana de Inclusión Educativa, 4(1), 65-82. Recuperado de http://www.rinace.net/rlei/numeros/vol4-num1/art3.pdf

Universidad Pedagógica Experimental Libertador. (2006). Manual de Trabajo de Grado de Especialización y Maestría y Tesis Doctorales. Venezuela: Fondo Editorial de la Universidad Pedagógica Experimental Libertador.

Venegas, María Eugenia. (2006). La Tercerización de la Formación Inicial Docente para la Educación Primaria en los Países Centroamericanos y República Dominicana. San José, Costa Rica: IDER.

Villegas, Margarita y González, Fredy. (2011). La investigación cualitativa de la vida cotidiana. Medio para la construcción de conocimiento sobre lo social a partir de lo individual. Psicoperspectivas. Individuo y Sociedad, 10(2), 35-59. 